\title{
Self Reflection of Virtuality in a Professional Association: a Compact Description of Mailing List Data
}

\begin{abstract}
This article presents an investigative description of the utilization of a mailing list in our own professional membership organization: IASSIST. As an electronic form of communication, the mailing list has supported and supports the IASSIST in moving the organization in the direction of a virtual community. The mailing list offers an answer to the jesting question: "Is there IASSIST life between IASSIST conferences?" This work contributes to methodology by offering a refined typology for the description and analysis of mailing lists in general, as well as a specific subject categorization for the IASSIST mailing list based on findings in the mailing list communication. The article gives a compact quantitative description of the key figures from the use of the IASSIST mailing list based upon the typology and categorizations. The analyzed data consist of emails from 32 months before the year 2000 millennium turn. A follow up on the analysis with more present email data is considered.
\end{abstract}

\section{Introduction}

Virtual organizations have been identified as real (Davidow and Malone, 1993) or real organizations sometimes viewed as imagined (Hedberg et al., 1997). The concept of the virtual community has now existed for a good 10 years (Rheingold, 1993). The virtuality emerges due to intense use of information technology corresponding to organizational arrangements that potentially and practically break the boundaries of time and space. In our time of virtuality, people no longer have to share the same space or be in the same time, as direct electronic communication can span the space, and relayed (asynchronous) electronic communication can span the time. A voluntary association - such as the IASSIST - is considered as both an organization and a community, and by applying electronic communications, such associations have the potential of growing into a virtual community.

\section{The aim: community and virtuality}

The object for investigation - IASSIST - is a small voluntary professional organization. The International Association for Social Science Information Service and Technology is an organization of professionals - typically from data archives and libraries - supporting research and education. The concept of "social science" is viewed in its most wide-ranging sense. IASSIST is a network and shows network externalities. "The more the merrier," but naturally this is balanced with the group of members actually being a group with common issues. Size has to be balanced with the necessary homogeneity within the group. The IASSIST organization was founded in 1974, and presently has about 300 members. The growth in members is mostly a result of the fact that "international" 25 years ago primarily meant "USWestern-European," but now more fully encompasses the globe. However, the IASSIST organization has not had a strong intention of membership growth into areas outside its professional base of data archivists, data librarians, and some social scientists. All of these affiliated with mostly university and/or research institutions. The existing IASSIST network can be viewed as comprising most of the relevant potential membership, but there is small but constant growth in regarding data materials as a resource available through libraries and archives.

A community is a togetherness that shares. Historically, the sharing within communities can take different forms, from the communion (with focus on sharing idealistic/religious beliefs) to the commune (that also practices sharing of material effects). All communities share meaning through communication. The knowledge shared in the community can be exemplified or statistically described. In this context the starting point is a look at how the sharing takes place.

Historically, social groupings have shared the same geographical locality and togetherness in time. Information technology breaks that barrier by making some sharing look and feel as reality, but it is "virtual reality." Virtuality is not reality, but it could be a dream or an imaginative creation. It can also be said that it surpasses reality - "it is surreal." The surreal found in arts and literature surpasses the objective reality as it includes individual subconscious elements to provide a more full understanding of our reality - even an antagonistic image of reality. Half a century ago the mass media turned the world into a "global village" (McLuhan, 1964). Virtuality contains this implosion in a synchronous form; virtuality provides an even more elaborated ability to react and utilize the new media of communication in obtaining closeness across barriers of 
time and space

\section{Selecting media for observation}

The communication between members of IASSIST has, from the start of the organization in 1974, taken place through conferences and also a newsletter/periodical. The membership has been among the "first movers" in the use of information technology (IT) for communication because their professional work included intensive use of IT and new media have been added to the list. From early on IASSIST has adopted the use of a mailing list and, later on, also a supporting web site. These media are briefly examined here for their capability to support virtuality and thus for founding the basis of an investigation into the virtuality of IASSIST:

Conference: The conferences are where IASSIST members meet face-to-face. Conferences are where people are situated in the same time and place and under a common heading and, furthermore, mostly detached from their obligations of everyday tasks. We may ask: "How and where do IASSIST members exchange views and share knowledge between the yearly conferences?" Or this could be formulated: "Is there life in IASSIST between conferences?"

Newsletter: $\quad$ Some life is added to the organization four times a year. Since 1977 there has existed a communicative channel for the membership associations in the form of a traditional printed and (surface) mail delivered membership newsletter (The IASSIST Quarterly or IQ). The content of the publication is primarily papers from presentations at the IASSIST conferences and the publication is not directly a medium for deliverance of data for research, although many articles have that subject as their focus. The articles can thus act as endorsements of data and directions for gaining access to data, as well as describe systems for data deliverance. Secondly, the IQ does not contain much communicative bi-directional interaction. Some references between articles in the IQ are found, but the periodical contains no actual debate. Although the newsletter is now also available in electronic form at the IASSIST web site (http://www.iassistdata.org/), the newsletter is considered without substantial independent importance for support of the virtual community. The argument is that the communication is one-way and that it started - and still exists - in the low-tech form of printed paper. However, the ease of access facilitated by the availability of the IQ on the web and the fact that IQ documents the objectives that members of IASSIST are pursuing in their work life count as assisting factors for IASSIST being a community.

Web site: The IASSIST web site has been conventional by creating access to some formal documents and more permanent announcements, especially the conferences. A bigger move forward was made when the IQ newsletter was published on the Internet (issues are available from 1993 onward). Furthermore, the web site features electronic copies of presentations made at the conferences, as the computer files (PowerPoint) are collected and presented in the original conference structure of days and sessions. The authors of this article have carried out some empirical research considering preferences for services at the web site. (This work is intended to be published later.) After the collection of the empirical data utilized in this article and after the survey of preferences mentioned above, the IASSIST has also recently opened a web log as a publishing and discussion board. This is obviously relevant for the concept of virtual community, but is not considered further in this article that is concentrating on the facilities available at the turn of the century.

Mailing list: $\quad$ In the early 1980s, communication by email was already an established fact among the IASSIST membership. Because of the international cooperation in the organization and the connection of data archives and libraries to mainframes for universities and research institutions, most members were connected to the forerunner of the Internet (ARPANET). The distribution of emails among members involved many copies to other members and was then consequently structured by establishing a mailing list for the membership. This mailing list has the central capability of permitting two-way communication.

Is the mailing list sufficient for constituting the infrastructure of IASSIST as a virtual community? The phrase "virtual community" was first used by Howard Rheingold (1993) in a book taking the point of departure in a mailing list (the WELL, "Whole Earth 'Lectronik Link"), so there is precedent for virtuality obtained through a mailing list. Consequently, we regard the IASSIST membership as a virtual community - in relation to the fact that the non-virtual communication is sparse - and we regard the mailing list as a valid medium for investigation.

\section{Mailing lists}

A mailing list is basically a communication duplication facility for email. Emails sent to the mailing list are being distributed or sent on to all members ("subscribers") of the mailing list. Hardie and Neon (1994) distinguish mailing lists into three types based on the applied filtering of information. The first one is the unmoderated list where everything sent to the list immediately is replicated to the subscribers, with no waiting time, but some messages might be annoying. The second one is the moderated list, where a moderator has to accept the input to the list; this requires work and introduces a varying time buffering of the accepted messages. However, the editing is necessary for the list not to be overwhelmed by unwanted commercials (spam). The third type of mailing list is the 
digest list which sometimes resembles a newsletter by having several subjects included and commented on by an editor. There will be only a few emails and they will appear with some regularity (e.g., monthly). The digest list is a one-way distribution list because communication travels only from the editor to the members. The categorization above is based upon whether all subscribers can make postings to the list directly, indirectly, or not at all. This categorization is paralleled by database users having levels and combinations of "read" and "write" permissions. The next aspect to consider is whether subscription to the mailing list is open to everybody or to a defined group of people.

The investigated mailing list of IASSIST is a moderated list, with only the membership as possible subscribers, and a subscriber can always both submit and receive emails from the list.

\section{Literature}

Mailing lists have been the subject of some earlier investigations. Fox and Roberts (1999) investigated the use of a mailing list amongst medical doctors in practice (GPs). The article demonstrates some anecdotal content analysis of the emails as citations from emails are presented, however the article contains neither statistical analysis nor description. Another approach was used in the study by Hannah (1999), where questionnaires were emailed to the subscribers of a mailing list to investigate the observed benefits of the mailing list. This was carried out without investigating the activity on the mailing list itself. $\mathrm{Xu}$ (1998) studied several mailing lists used by system librarians. Emails from one of the lists were examined - for a two-month period of time - and questionnaires were sent to several categories of users (or user roles). An equal short period of mailing list traffic was examined by Burton (1994). Empirical later investigations of several mailing list and their members and in particular their non-participants ("lurkers") are found in Stegbauer \& Rausch (2002).

\section{Available data}

The current investigation of a mailing list is also an endeavor into the investigation and demonstration of the obtainable level of information from the Internet without actually asking for individual approval and consent from the subjects being investigated. Often the data of the mailing list is placed on the Internet and easily and directly available. In this case, clearance to access the IASSIST archives of the mailing list was given to the researchers by the organization. But many mailing lists are publicly open for retrieval and they often have searching facilities for the identification of threads of interest, and contributions to mailing lists are sometimes stored for easier retrieval and presentation through the use of a web-application. In the use of data in this article, precautions have been taken not to directly reveal the identity of people and their expressed opinions. However, the information for this kind of monitoring of activities on the Internet and especially on mailing lists are available. King (1996) discusses the ethical aspects of the availability of communication data and Burton (1994) also addresses the ethical aspects by sending out information to the mailing list under investigation.

\section{Themes of analysis}

The analysis will present descriptive answers to the following dimensions and questions that became apparent when describing the mailing list from some obvious viewpoints of interest:

Active-Passive: Who is sending to the mailing list? The senders are all identifiable as email addresses, thus permitting determination and comparison of the active addresses. Secondly, the members of the mailing list are also identified as email addresses (as the addresses being sent to) and these are the members of the IASSIST. The senders can be investigated and compared to the passive non-senders. (General communication and mailing list as media).

Nationality: With some accepted uncertainty, email addresses may indicate nationality. The main validity problem is that USA becomes the default used when a nationality is not directly given. But this is considered a minor problem in this context because most members outside the USA can be said to belong to educational institutions that in their email are directly attached to a nation. Had it been commercial institutions, this solution might not have had sufficient validity. (Internationality of an organization).

Officer-Member: Are certain membership groups more active in posting information to the mailing list? A list of persons performing official functions (officers) is available as another mailing list is used for administrative purposes. Some differences in communication patterns between officers and regular members are expected. (Hierarchy in the organization).

Modes: WWhat modes of communication take place on the mailing list? Some emails stand isolated ("single") while other emails are connected and can be combined into threads with regard to the same subject and within a defined period of time. Within a thread, the single email is classified according to its role in the thread as "initiation" or "reply." (Communication initiator or follower).

\section{Data and method}

The underlying unit of analysis is a single email and all emails are stored and retrievable from the list server from December 1991 and onward. A technical shift occurred in May 1997, so to secure the comparison issue the investigation period includes 32 months (from May 1997 until December 1999). Because the same person could 
have several email addresses and a person could have changed his or her email address during the 32-month period, a considerable process of match-merging by userwritten matching software took place for performing a valid aggregation and shift of analysis unit from emails to persons (participants on the IASSIST mailing list).

\section{Findings and figures}

The total material consists of 691 emails that have been sent from 162 persons. The membership on the mailing list consists of 265 persons, i.e., 103 persons did not post email to the list during the investigated period of time. The 691 emails sent from 265 potential posters of mail results in an average of 2.6 emails per person (or approximately one email to the mailing list per year per person).

When comparing the figures for within and outside North America, it appears that the ratio for mail per person is 3.1 versus 1.4. The higher figure among members from North America supports the findings of US-dominance in earlier mentioned studies (Xu, 1998; Burton, 1994). subscribers can be considered content and regard the list as providing useful information as in direct performance improvement via computer-mediated communication (Rice, 1994).

The emails were combined into threads or single emails, where a "single email" has no response from the list. The separation into threads was done by user written software that stripped the title field down to essential information, and when titles matched and emails were close in time they were considered to belong to the same thread. A thread with only one email is a "single." So if an email is not a "reply" it is a starting email that can be categorized as either a "single" (without any later responding emails and not part of a thread) or an "initiation" (the start of a regular thread). Three hundred of the emails were single and had no follow up; the remaining 391 emails were combined into 125 threads (as shown in table 1 below). The content of the emails are not analyzed in this context. However, some single emails never expected any response as they are often email announcements (e.g., emails announcing the availability of a new dataset).

The membership of 265 persons can be subdivided into 31 persons belonging to the group of IASSIST officials and 234 regular members. Seven of the officers have not participated in the mailing list. The ratio of emails from 24 active officers

(280 mails) is 11.7 , which is significantly higher than the 138 active nonofficers sending 411 mails (ratio 3.0). A regression model shows that the binary office variable is highly significant and explains 20.1 percent of the variation, and that the addition of the geographic variable and the interaction term only accounts for an extra 3.6 percent of the variation. In this investigation, the office variable is consequently considered a better explanatory variable for what otherwise appears as a regional dominance.

The figures above account for the fact that 96 non-officer members are inactive in submitting to the list. Inequality in electronic communication has in several contexts been the subject for studies (Sproull and Kiesler, 1991, p. 60), and terms like "quiet observers" (Ha, 1997; Xu, 1998) or "lurkers" (Fox and Roberts, 1999; Stegbauer \& Rausch, 2002) have been introduced. However, it is only reliable to conclude that persons responding to the list are reading the emails - or more precisely just that email. However, the rational behaviour of a mailing list member who never reads the mails would be to unsubscribe to the list. Inactive
The officers were initiators of 213 (149+64) occurrences while the regular membership started $212(151+61)$.

The emails in table 1 are produced by 24 officers and 138 regular members. The officers are thus characterized as more frequent starters of emails (an average of 8.9 emails per officer) compared to the regular membership (with an average of 1.5 emails). With respect to posting replies to the list, the difference between the two groups is not that extreme (averages 2.8 and 1.4). Furthermore, there is a clear relationship between being an active initiator and being an active replier. The number of replies correlated to the number of starts from the same person was much higher among the officers than among the regular membership (Pearson 0.66 versus 0.20 ). This means that a small group of the officers are very active in their use of the mailing list.

\section{Conclusion}

The article has demonstrated a utilization of data being available on the Internet - the data driven approach - and we have not created or collected other data for this 
particular research task. We regard this as defendable ethical research as individuals are not being exposed, but we welcome a debate on surveillance of individuals without their given consent through the materials available or traces left on the Internet. The findings of the descriptive analysis include explanation of email participation, and it was found that the crucial variable for high activity was whether a person had official duties within the organization.

The mailing list forms a virtual community - and like for a virtual organization - a virtual community is also characterized by blurred boundaries. In further investigations we have used (but not yet published) questionnaire data to look for evidence of further virtuality in terms of boundary crossing where non-formal (nonpaying) members enjoy close to the same benefits as the regular membership. Furthermore, a follow-up study on the mailing list ( 5 years after) is being considered

* This article appeared in another form in the proceedings from the 11th International Conference on HumanComputer Interaction (2005). Some of the figures were earlier presented at the IASSIST 2001 Conference in Amsterdam as "Professional associations in transition to virtual communities for collaboration: the case of IASSIST."

Repke de Vries, Department of Public Services at The Royal Library of the Netherlands.

Karsten Boye Rasmussen, Department of Marketing and Management at University of Southern Denmark. Contact e-mail:kbr@sam.sdu.dk.

\section{References}

Batinic, B., Reips, U.-D. \& Bosnjak, M. (2002). Online Social Sciences. Hogrefe \& Huber, Göttingen.

Burton, P.F. (1994). Electronic mail as an academic discussion forum; 1994; Journal of Documentation, 50(2), 99-110.

Davidow, W. H. \& Malone, M.S. (1993). The Virtual Corporation; Harper Business; New York, N.Y.

Donath, J. S. (1996). Identity and deception in the virtual community. In Smith \& Kollock (Ed.), Communities in Cyberspace; Routledge

Fox, N.; and Roberts, C. (1999). GPs in cyberspace, the sociology of a "Virtual Community"; The Sociological Review (Nov. 1999), 47 (4), 643-671.

Ha, L. (1997). Active participation and quiet observation of adforum subscribers; Journal of Advertising Education 1997, 2(1), 4-19.
Hannah, R. L. (1999). A Case Study of Benefits-L Subscribers; Benefits Quarterly; Third Quarter 1999, 24-29.

Hardie, E.T. \& Neon, V. (1994). Internet: mailing lists; PTR Prentice-Hall; Englewood Cliffs, NJ.

Hedberg, B.; Dahlgren, G.; Hansson, J. \& Olve, N.G. (1997). Virtual organizations and beyond: discover imaginary systems; Wiley; Chichester.

King, S.A. (1996). Researching Internet Communities: Proposed Ethical Guidelines for the Reporting of Results; 1996 Information Society, 12:119-27.

McLuhan, M.. (1964). Understanding Media: The Extensions of Man, Routledge Classics.

Rasmussen, K.B.; and de Vries, R. (2005). Growing Virtuality in a Professional Association - A Data Driven Approach. 11th International Conference on HumanComputer Interaction (PDF proceedings CD).

Rheingold, H. (1993). The Virtual Community; AddisonWesley; New York.

Rice, R. (1994). Relating electronic mail use and network structure to R\&D work networks and performance; 1994; Journal of Management Information Systems 11 (1) 9-29.

Sproull, L.; and Kiesler, S. (1991). Connections: New Ways of Working in the networked Organization; MIT Press.

Stegbauer,C. \& Rausch,A. (2002). Lurkers in Mailing Lists. In: Online Social Sciences, Batinic,B. (ed.), 263-274.

$\mathrm{Xu}, \mathrm{H}$. (1998). Global Access and Its Implications: The Use of Mailing Lists by System Librarians; Volume 351998 Proceedings of the ASIS conference "Information access in the global information economy"; 427-444 